Theor Appl Genet (1993) 86:1001-1006

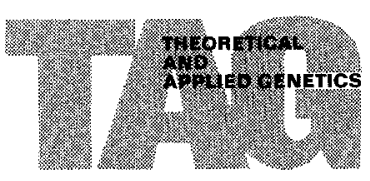

(C) Springer-Verlag 1993

\title{
Determination of ploidy level and nuclear DNA content in blueberry by flow cytometry
}

\author{
D. E. Costich ${ }^{1}$, R. Ortiz ${ }^{2}$, T. R. Meagher ${ }^{1}$, L. P. Bruederle ${ }^{2, *}$, N. Vorsa ${ }^{2}$ \\ ${ }^{1}$ Department of Biological Sciences, Rutgers University, P.O. Box 1059, Piscataway, NJ 08855-1059, USA \\ ${ }^{2}$ Blueberry and Cranberry Research Center, Cook College, Rutgers University, Chatsworth, NJ 08019, USA
}

Received: 10 January 1992 / Accepted: 28 January 1993

\begin{abstract}
The technique of DNA flow cytometry was used to study variation in DNA content among different ploidy levels, as well as among diploid species, of Vaccinium section Cyanococcus. In a sample of plants of varying ploidy level, the relative fluorescence intensity (RFI) of nuclei stained with propidium iodide was a function of the number of chromosome sets (x), as represented by the linear equation $\mathrm{RFI}=3.7 \mathrm{x}-2.3$ $\left(\mathrm{r}^{2}=95 \%\right)$. The data indicated that DNA flow cytometry could be useful for the determination of ploidy level at the seedling stage in blueberry. They also suggest that "conventional polyploid evolution" has occurred in this section of the genus Vaccinium with an increase in nuclear DNA content concurrent with the increase in chromosome number. The nuclear DNA content of diploid species of Vaccinium section Cyanococcus was estimated from the relationship of the observed RFI to an internal known DNA standard (trout red blood cells). A nested analysis of variance indicated significant variation among species, as well as among populations within species, in nuclear DNA content, although this variation was small compared to the variation among ploidy levels. The variation in nuclear DNA content corresponded to the phylogenetic relationships among species determined from previous studies.
\end{abstract}

Key words: Vaccinium - Genome size - Nuclear DNA content - Polyploid evolution

\footnotetext{
Communicated by A. L. Kahler

* Present address: Biology Department, The University of Michigan-Flint, MI 48502-2186, USA

Correspondence to: $\mathrm{N}$. Vorsa
}

\section{Introduction}

In polyploid crop species, desirable characteristics often exist in species having ploidy levels other than that of the cultivated forms. Heteroploid crosses, crosses having parents of different ploidy levels, are often attempted to facilitate introgression of desirable genes into the cultivated species. However, heteroploid crosses are complicated by the fact that they can generate progeny of varying ploidy levels. In crops where somatic chromosome counts are difficult, and which have a long generation interval for meiotic analysis, a rapid method for establishing the ploidy level at the seedling stage would be especially useful. In addition, interspecific variation for genomic DNA content may be an important factor in the success of interspecific crosses: determining the phylogenetic nature of variation of genomic DNA content among wild relatives may serve as a guide to their prospective utility in breeding programs.

Blueberry species of eastern North America belong to the section Cyanococcus A. Gray of the genus Vaccinium L. Controversy still exists about the taxonomic treatment of this section (Vander Kloet 1988); however, at least six diploid (2x) species are commonly recognized, $V$. boreale Hall and Aalders, $V$. darrowi Camp, V. myrtilloides Michx., V. pallidum Ait. and $V$. tenellum Ait. Bruederle and Vorsa (1990) presented genetic data supporting the recognition of an additional species, V. elliottii Chapm. Vander Kloet (1988) recognized three tetraploid $(4 \mathrm{x})$ species, $V$. angustifolium Ait., $V$. hirsutum Buckley and $V$. myrsinites Lam., in addition to $V$. corymbosum L., which exists as $2 \mathrm{x}, 4 \mathrm{x}$ and hexaploid $(6 \mathrm{x})$ cytotypes. Interspecific triploid (3x), pentaploid (5x), octoploid $(8 x)$ and nanoploid (9x) hybrids have been obtained (Vorsa 1988; Vorsa 
and Ballington 1991; Draper, personal communication).

Wild species are an important source of favorable alleles for blueberry genetic improvement (Galletta 1975; Sharpe and Sherman 1971). The production of $2 \mathrm{n}$ gametes by 2x (Megalos and Ballington 1988; Sharpe and Sherman 1971; Vorsa and Ballington 1991), 3x (Vorsa and Ballington 1991) and 5x (Vorsa et al. $1987 \mathrm{a}, \mathrm{b})$ cytotypes provides a means of transferring these genes to the cultivated $4 \mathrm{x}$ and $6 \mathrm{x} V$. corymbosum gene pool. Moreover, aneuploids, especially trisomics, offer the opportunity for both cytogenetic and genetic studies in this species (Vorsa et al. 1986). However, the detection of $4 \mathrm{x}$ progeny from $4 \mathrm{x} \times 2 \mathrm{x}$ and $2 \mathrm{x} \times 4 \mathrm{x}$ crosses, $6 \mathrm{x}$ progeny (from intermating $4 \mathrm{x}$ parents, one with $2 \mathrm{n}$ gametes), or aneuploids (from $3 \mathrm{x} \times 2 \mathrm{x}$ or $5 \mathrm{x} \times 4 \mathrm{x}$ ) takes time and requires extensive cytological work, because chromosome counting of meiotic material is necessary. Normally, this is done using pollen mother cells at anaphase-I and anaphase-II (Vorsa 1984). Therefore, an early and easy method for the determination of chromosome number in the interspecific-heteroploid hybrids is desirable. In this way, aneuploids, and $4 \mathrm{x}$ and $6 \mathrm{x}$ hybrids can be identified in the early stages of development, leading to a saving of both resources and time.

DNA flow cytometry, which measures the fluorescence of a large number of stained nuclei within seconds, provides an estimate of nuclear DNA content within somatic plant tissues (Galbraith et al. 1983; Arumuganathan and Earle 1991b). The application of flow cytometry to nuclei stained with propidium iodide has been directly compared with more tedious traditional approaches to measuring plant cell DNA content, and this newer approach has been found to give equivalent results (Michaelson et al. 1991). Chromosome number has often been found to be significantly correlated with nuclear DNA content (Verma and Rees 1974; Black and Beckman 1983). In this regard, DNA flow cytometry has been used to determine ploidy levels in plants (De Laat et al. 1987; Keeler et al. 1987; De Rocher et al. 1990) or sex in dioecious species (Costich et al. 1991) using nonflowering materials. Moreover, the estimation of nuclear DNA content is important for plant genome mapping as well as for developing strategies for plant gene isolation (Arumuganathan and Earle 1991a).

The objectives of our work were three-fold: first, to investigate the effectiveness of DNA flow cytometry in determining the ploidy level in blueberry; second, to measure the variation in nuclear DNA content in diploid species of the section Cyanococcus; and third, to examine the relationship between variation in DNA content and interspecific genetic distance.

\section{Materials and methods}

\section{Sample collection and preparation}

Blueberry leaves were sampled from the stock collection maintained at the Blueberry and Cranberry Research Center of Rutgers University (Chatsworth, N.J.). Evaluation of different ploidy levels made use of genotypes ranging from $2 \mathrm{x}$ to $6 \mathrm{x}$ derived from various breeding experiments at the Center. Ploidy levels were determined through cytogenetic analyses as used in previous studies (Vorsa 1984, 1988, unpublished data; Vorsa and Ballington 1991). The study of DNA content variation among diploid species in the section Cyanococcus made use of collections that were part of a broad survey of genetic diversity in blueberry species (Bruederle and Vorsa 1990; Bruederle et al. 1991). The plants in that survey were sampled from broadly dispersed natural populations, and individuals within populations were sampled on a grid at intervals of no less than $20 \mathrm{~m}$ between samples in order to ensure that different genotypes, rather than clonal replicates, were collected. Subsequent electrophoretic studies of those samples indicated levels of genetic diversity consistent with each sample representing a unique genotype (e.g., Bruederle et al. 1991).

Samples for flow cytometry were prepared using $50 \mathrm{mg}$ of leaf tissue per genotype. The protocol used for isolating and staining nuclei follows Arumuganathan and Earle (1991b) but with modifications that greatly reduced the amount of debris in the samples (Dickson et al. 1992). Propidium iodide was eliminated from the chopping buffer " $1991 \mathrm{~b})$ and $1 \%$ PVP added. Leaf tissue was thinly sliced with a sharp scalpel on ice in Solution $A$, and subsequently filtered through 30- $\mu \mathrm{m}$ nylon mesh. It was then centrifuged at high speed $(15,000 \mathrm{rpm})$ for $30 \mathrm{~s}$ and resuspended in $200 \mu \mathrm{l}$ of a solution (" $\mathrm{B}$ ") containing Solution A, $2 \%$ propidium iodide stock solution $(5 \mathrm{mg} / \mathrm{ml}), 0.25 \%$ DNAase-free RNAase (Boehringer Mannheim Cat. No. 1119915) and rainbow trout red blood cells (TRBC) (used as a standard for DNA content measurements). Fresh rainbow trout blood was collected in heparinized tubes and kept under refrigeration for approximately 1 week prior to the experiment. Our experience with TRBC is that DNA stainability remains unchanged for up to 2-3 weeks of refrigeration; however, the concentration of measurable TRBC decreases with time. In order to obtain several hundred red blood cells per sample, an $0.065 \%$ concentration of TRBC Stock Solution $[1: 25$ dilution of TRBC in Alsever's solution (Sigma No. A-3551)] in Solution B was used. After a 15 -min incubation at $37^{\circ} \mathrm{C}$, to enable the RNAase to eliminate any residual RNA, the samples were kept on ice and subjected to flow cytometry within a few hours. Nuclear preparations of this type do not store well and need to be run the same day.

\section{DNA flow cytometry}

The samples of suspended nuclei were analyzed using an EPICS Profile flow cytometer (Coulter Electronics, Hialeah, Florida) equipped with an Argon ion laser (25 mW, Omnichrome 150) emitting at $488 \mathrm{~nm}$. The red fluorescence emission signal of propidium iodide was processed off of a $600 \mathrm{~nm}$ short band pass dichroic filter and through $457-502 \mathrm{~nm}$ long pass laser-blocking and $625 \mathrm{~nm}$ band pass filters.

Blueberry samples typically contain debris that can be excluded from the analysis by appropriate bitmap placement (Fig. 1). The relative fluorescence intensity (RFI) of counted particles was determined on a log scale.

Emperimental procedure

In order to assess the relationship between ploidy level and RFI, DNA flow cytometry was performed on 20 genotypes: seven $2 x$, 
two $3 x$, three $4 x$, five $5 x$ and three $6 x$ (see Table 1 ). The TRBC internal standard was not used in this experiment because the tetraploid plants yielded a cellular DNA content almost identical to that of TRBC. Thus, the TRBC internal standard would have interfered with the output. As noted below, the differences among samples of different ploidy levels were such that they were clearly distinguishable on the basis of RFI alone. The samples were analyzed in random sequence on the flow cytometer in order to statistically account for laser drift and other sources of machine error. A second replicate series of measurements was performed on the same samples following a second filtration. One of the $3 \mathrm{x}$ genotypes measured was not included in the subsequent analysis because the replicated readings were widely divergent; it was the only sample which showed this degree of variation.

The estimation of DNA content in the $2 x$ species was based on three genotypes sampled from each of three populations for each species. As noted above, care was taken in the original sampling of plants to ensure that each sample consisted of a unique genotype; populations were defined as geographically distinct localities. The DNA standard for this experiment was TRBC, so that the DNA content in picograms for each sample was determined by dividing the blueberry RFI by the TRBC RFI and multiplying by 5.05 , the published mean DNA content of TRBC (Arumuganathan and Earle 1991b).

In order to assess the relationship between interspecific genetic differentiation and variation in nuclear DNA content, a distance matrix based on the difference between species in nuclear DNA content was generated. This distance matrix was then statistically compared to genetic distances among species as determined in previous investigations (Bruederle and Vorsa 1990, unpublished data).

\section{Statistical analysis}

The statistical relationship between ploidy level and RFI was determined through regression analysis. The amount of the total variation in RFI explained by ploidy was evaluated through the coefficient of determination $\left(\mathrm{r}^{2}\right)$ (Steel and Torrie 1980).
Variation in DNA content among diploid species of the section Cyanococcus was evaluated using a nested analysis of variance (ANOVA) (Sokal and Rohlf 1981), in which variation among genotypes was nested within populations, which in turn were nested within species. The analysis was performed in SAS (SAS Institute Inc. 1985); error mean squares for successively higher levels in the nested ANOVA were determined by evaluation of significance at lower levels in the analysis. Certain genotypes within some of the populations yielded too few nuclei to generate a useful estimate of DNA content, resulting in unbalanced sample sizes in this analysis; consequently, type III sums of squares were used throughout.

The relationship between interspecific differences in DNA content and genetic distance between species was evaluated by performing a Mantel test of matrix concordance (Smouse et al. 1986). The genetic distance estimates were based on previous studies by Bruederle and Vorsa (1990, unpublished data). One thousand iterations of the distance matrices were performed in order to determine a bootstrap-based significance level (Efron. 1982) for the Mantel test statistic.

\section{Results}

There was a highly significant linear relationship between ploidy level and RFI for blueberry species and hybrids (Table 1, Fig. 2). Ploidy level accounted for $95 \%$ of the variation in RFI. The extent of differentiation between ploidy levels was much higher than variation within ploidy levels, so that the flow cytometry protocol developed in this study could be used to resolve the ploidy level of samples taken from blueberry plants of unknown ploidy.

Examination of nuclear DNA content in different species of one ploidy level $(2 \mathrm{x})$ showed significant

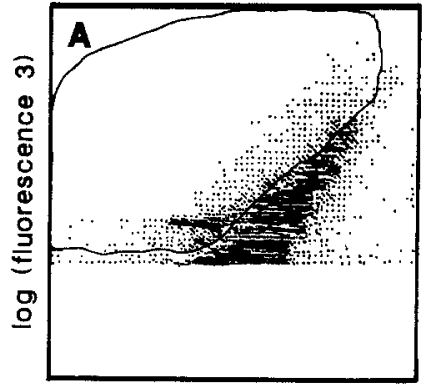

$\log$ (forward scatter)

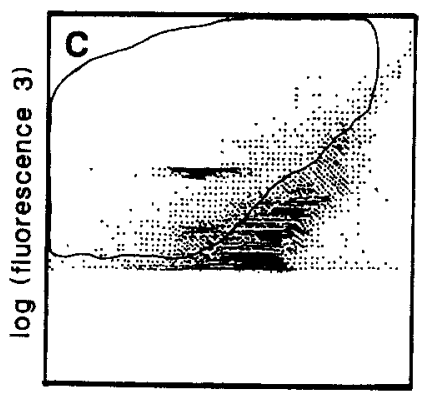

$\log$ (forward scatter)

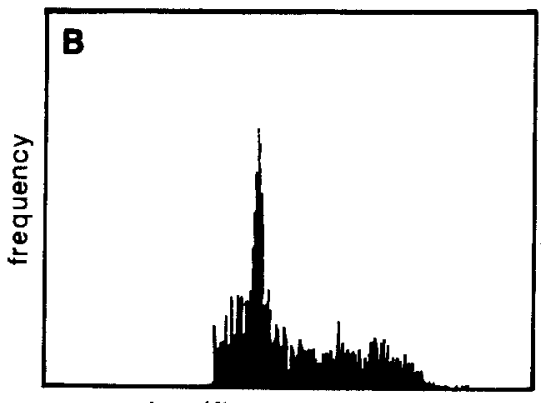

$\log$ (fluorescence 3)

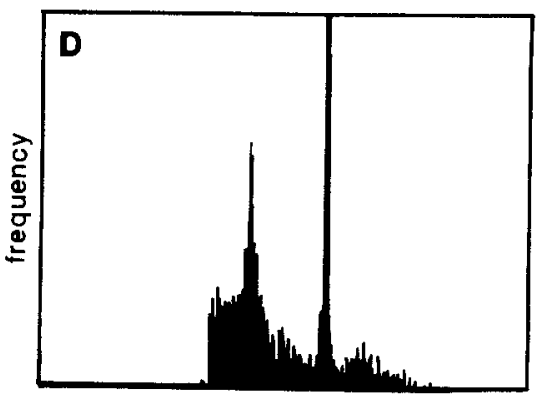

$\log$ (fluorescence 3)
Fig. 1A-D. Example of flow cytometry output for blueberry samples. Panel A shows a plot of relative fluorescence intensity (RFI) versus forward scatter, a measure of particle size, for a $2 \mathrm{x}$ genotype of Vaccinium pallidum. The bitmap indicated in panel $\mathbf{A}$ screens out particles to be counted in subsequent analysis. Panel B shows the frequency distribution of RFI for particles screened in the bitmap in panel $\mathbf{A}$. Panels $\mathbf{C}$ and $\mathrm{D}$ represent flow cytometry results for the same genotype with the inclusion of a TRBC standard, yielding an additional peak in panel $\mathbf{D}$ 
Table 1. Flow cytometric measurements of relative fluorescence intensity (RFI in log scale) of propidium iodide-stained nuclei from blueberry of varying ploidy

\begin{tabular}{lllr}
\hline Accession & Ploidy & Species & RFI \\
\hline NJ 88.06 & $2 \mathrm{x}$ & V. darrowi & 6.02 \\
NJ 88.16 & $2 \mathrm{x}$ & V. elliottii & 5.18 \\
NJ 88.31 & $2 \mathrm{x}$ & V. tenellum & 5.54 \\
NJ 87.57 & $2 \mathrm{x}$ & V. pallidum & 5.38 \\
NJ 87.43 & $2 \mathrm{x}$ & V. myrtilloides & 5.35 \\
NJ 88.29 & $2 \mathrm{x}$ & V. boreale & 5.58 \\
NC 84.6b & $2 \mathrm{x}$ & V. corymbosum & 7.04 \\
Jersey $\times$ ten 2 & $3 \mathrm{x}$ & V. corymbosum $\times$ V. tenellum & 8.28 \\
NJ 871 & $3 \mathrm{x}$ & V. corymbosum $\times$ V. darrowi & 8.32 \\
NJ 88.07 & $4 \mathrm{x}$ & V. myrsinites & 11.40 \\
NJ 88.23 & $4 \mathrm{x}$ & V. angustifolium & 10.54 \\
NJ 89.12 & $4 \mathrm{x}$ & V. pallidum & 10.55 \\
Pentaploid 1 & $5 \mathrm{x}$ & $(4 \mathrm{x} \times 6 \mathrm{x})$ V. corymbosum & 15.12 \\
Pentaploid 2 & $5 \mathrm{x}$ & $(4 \mathrm{x} \times 6 \mathrm{x})$ V. corymbosum & 15.40 \\
MS 149 & $5 \mathrm{x}$ & $(4 \mathrm{x} \times 6 \mathrm{x})$ V. corymbosum & 14.73 \\
Pentaploid $3^{\mathrm{b}}$ & $5 \mathrm{x}$ & $(6 \mathrm{x} \times 4 \mathrm{x})$ V. corymbosum & 15.94 \\
Pentaploid 4 & $5 \mathrm{x}$ & $(6 \mathrm{x} \times 4 \mathrm{x})$ V. corymbosum & 15.90 \\
Tifblue & $6 \mathrm{x}$ & V. corymbosum & 22.58 \\
Garden Blue & $6 \mathrm{x}$ & V. corymbosum & 22.27 \\
Brightwell & $6 \mathrm{x}$ & V. corymbosum & 20.46 \\
\hline
\end{tabular}

a Derived from Rancocas $\times$ Tifblue cross

${ }^{b}$ Derived from Woodard $\times$ Elliott cross

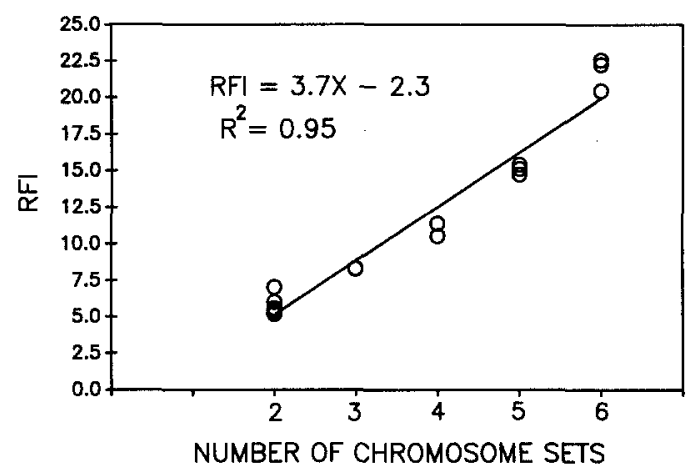

Fig. 2. Relative fluorescence intensity (RFI) of propidium iodide-stained nuclear DNA of blueberry plants as a function of the number of chromosome sets. The regression presented is highly significant $\left(\mathrm{F}_{1,18}=353, P \leq 0.0001\right)$

variation among species as well as among populations within species (Tables 2,3). Although these differences are small relative to the differences between ploidy levels, they indicate that there may be polymorphism for chromosome size within blueberries.

The variation in nuclear DNA content among $2 \mathrm{x}$ blueberry species appears to be related to the extent of their phylogenetic divergence. Our estimate of the Mantel statistic was 1.19 with a bootstrap-based $P$ level of 0.016 . This means that out of 1000 random
Table 2. Nuclear DNA content (picograms) of $2 \mathrm{x}$ Vaccinium species of the section Cyanococcus

\begin{tabular}{lllll}
\hline Species & $\begin{array}{l}\text { No. } \\
\text { plants }\end{array}$ & \multicolumn{2}{l}{ DNA content (pg) } & $\begin{array}{l}\text { Duncan's } \\
\text { groupings }\end{array}$ \\
\cline { 3 - 4 } & & Mean & SD & \\
\hline V. boreale & 5 & 1.18 & 0.03 & $\mathrm{~A}$ \\
V. pallidum & 9 & 1.21 & 0.02 & $\mathrm{AB}$ \\
V. elliottii & 7 & 1.26 & 0.03 & $\mathrm{BC}$ \\
V. myrtilloides & 4 & 1.26 & 0.06 & $\mathrm{BC}$ \\
V. tenellum & 6 & 1.30 & 0.03 & $\mathrm{CD}$ \\
V. darrowi & 7 & 1.31 & 0.03 & $\mathrm{D}$ \\
V. corymbosum & 7 & 1.33 & 0.12 & $\mathrm{D}$ \\
\hline
\end{tabular}

a Means with the same letter are not significantly different at the 0.05 level

Table 3. Nested analysis of variance among $2 \mathrm{x}$ species of Vaccinium section Cyanococcus

\begin{tabular}{lrrrl}
\hline Source & $d f$ & MS & Error MS & $\begin{array}{l}\text { F } \\
\text { ratio }\end{array}$ \\
\hline Species (S) & 6 & 0.0174 & P within S & $3.12^{*}$ \\
Populations (P) within S & 12 & 0.0056 & I within P & $2.50^{*}$ \\
Individuals (I) within P & 26 & 0.0022 & & \\
\hline
\end{tabular}

* $P<0.05$

permutations of our genetic distance/nuclear DNA difference matrices, only 16 yielded Mantel estimates greater than our observed matrices. Thus there is a positive correlation between genetic distance or divergence between species and the extent of differentiation in nuclear DNA content as determined by flow cytometry.

\section{Discussion and conclusion}

The results indicated that DNA flow cytometry can be used to determine ploidy level in the early stages of development (seedling) of blueberry plants. This technique will be particularly useful for plants derived from heteroploid crosses in which parent(s) produce $2 \mathrm{n}$ gametes. In this way, time and resources can be saved by keeping only those plants generated from sexual polyploidization. However, the current level of resolution of flow cytometry would not enable the detection of aneuploids in blueberry, although this approach has detected aneuploid variation in mammalian cells. Improvement of resolution to enable detection of aneuploids in blueberry is a clear objective for further development of this technique.

Previous workers have noted the cytological similarity among $2 \mathrm{x}$ species of Vaccinium section Cyanococcus, even to the point of suggesting that the same 
idiogram can be applied across species (Hall and Galletta 1971). Our results indicate that although similarities have been observed among karyotypes of these species, there is clearly interspecific variation in either genomic DNA content or composition. Differences between species observed in the present study appear to be attributable to DNA content; however, they are subtle enough that our results could reflect small changes in stainability of cells resulting from variation in chromosome structure. Under either scenario, the variation detected among populations within species is sufficient to support ongoing evolution of chromosome composition in blueberry.

One observed trend in the evolution of genome size in plants is that adaptive differentiation of a group of related species is accompanied by a gradual decrease in genome size as species become more specialized (Price 1976). The current differences among blueberry species are still small, but detectable, suggesting that these species may be at an early stage in the evolution of such specialization. It is of interest in this context to note that the species with the largest genome, V. corymbosum, had the highest variance in genome size. $V$. darrowi, which also had a relatively large genome, is regarded as the ancestral species for the section. While these trends are of interest, there are too few diploid species in Cyanococcus to draw any strong phylogenetic conclusions.

The overall genome size of blueberry, as determined here, can be directly compared to other cultivated species. The nuclear DNA content estimates for the diploid species yield an average haploid genome size of $0.63 \pm 0.03 \mathrm{pg}$. Thus the genome size (in million base pairs, $\mathrm{Mbp}$ ) can be estimated as $608 \mathrm{Mbp}$ /haploid genome by assuming that $1 \mathrm{pg}$ of nuclear DNA has $965 \mathrm{Mbp}$ (Bennett and Smith 1976). This estimate for blueberry is almost four times greater than that found for Arabidopsis (Arumuganathan and Earle 1991a), five times smaller than that estimated for corn (Michaelson et al. 1991), almost half the size of the tomato genome (Arumuganathan and Earle 1991a), and substantially larger than the genome sizes of fruit species such as papaya, mango, apricot, sweet cherry, peach, orange and raspberry (Arumuganathan and Earle 1991a).

The level of variation among $2 x$ species in nuclear DNA content relative to the magnitude of variation among ploidy levels was low, suggesting that "conventional polyploid evolution" has occurred in the section Cyanococcus. In effect, there has been a multiplication of the basic chromosome number but chromosome size and DNA content per chromosome in the polyploid species remain relatively constant. Therefore, the large phenotypic variation observed among the Vaccinium species of the section Cyanococcus are probably the result of allelic differences at homologous loci rather than a consequence of polyploidy per se.
DNA flow cytometry provides the opportunity to study the relationship of species in the section $C y$ anococcus with species of other sections in the genus Vaccinium. In this way, it may be possible to determine whether "cryptopolyploidy" (an increase in DNA amount and chromosome size without increasing chromosome number) occurred in this genus. For example, the total nuclear DNA content for another $2 \mathrm{x}$ species in the genus Vaccinium, cranberry (V. macrocarpon section Oxycoccus), was estimated as $1.16 \pm$ $0.04 \mathrm{pg}$ (Costich et al., unpublished data), which was not notably different than that estimated for the other $2 \mathrm{x}$ species in the section Cyanococcus. This finding was expected because the total length of cranberry chromosomes is not significantly different than that found in the $2 \mathrm{x}$ blueberry species of the section Cyanococcus (Hall and Galletta 1971). DNA flow cytometry also provides the opportunity to investigate chromosome differentiation, due to changes in DNA content and its organization within the chromosome, within the genus Vaccinium. It is not difficult to envision that the magnitude of such differentiation could play a role in the lack of chromosome pairing in both intersectional and interspecific intrasectional hybrids.

Acknowledgements. The authors thank Drs. K. Arumuganathan (Cornell University) and E. J. Yurkow (Rutgers University) for their helpful suggestions to improve the protocol used in this research, and to Dr. Mark Ehlenfeldt (USDA-Chatsworth, N.J.) for his critical reading of this manuscript. We thank J. Matthews and E. Washuta at the Pequest State Fish Hatchery (Oxford, N.J.) for supplying the rainbow trout blood. D.E.C. was partially supported by a Charles and Johanna Busch Postdoctoral Fellowship from Rutgers University. This is New Jersey Agricultural Experiment Station Publication No. D-12163-17-91, supported by State and U.S. Federal funds, USDA-ARS Specific Cooperative Agreement No. 58-3615-9-068.

\section{References}

Arumuganathan K, Earle ED (1991a) Nuclear DNA content of some important plant species. Plant Mol Biol Rep 9: 206-216

Arumuganathan K, Earle ED (1991b) Estimation of nuclear DNA content of plants by flow cytometry. Plant Mol Biol Rep 9:217-229

Bennett MD, Smith JB (1976) Nuclear DNA amounts in angiosperms. Phil Trans R Soc Lond B 274:227-274

Black CL, Beckmann RL (1983) The variability of nuclear DNA and its implications for polyploidy in white ash (Fraxinus Americana L.: Oleaceae). Am J Bot 70:1420-1423

Bruederle LP, Vorsa N (1990) Systematic relationships among the diploid blueberry species (Vaccinium $\$$ Cyanococcus A. Gray; Ericaceae) (abstract). Am J Bot 77:122

Bruederle LP, Vorsa N, Ballington JR (1991) Population genetic structure in diploid blueberry Vaccinium section Cyanococcus (Ericaceae). Am J Bot 78:230-237

Costich DE, Meagher TR, Yurkow EJ (1991) A rapid means of sex identification in Silene latifolia by use of flow cytometry. Plant Mol Biol Rep 9:359-370 
De Laat AMM, Gohde W, Vogelzang MJDC (1987) Determination of ploidy of single plants and plant populations by flow cytometry. Plant Breed 99:303-307

De Rocher EJ, Harkins KR, Galbraith DW, Bohnert HJ (1990) Developmentally regulated systemic endopolyploidy in succulents with small genomes. Science 250:99-101

Dickson EE, Arumuganathan K, Kresovich S, Doyle JJ (1992) Nuclear DNA content variation within the Rosaceae. Am J Bot 79:1081-1086

Efron B (1982) The jackknife, the bootstrap and other resampling plans. SIAM, Philadelphia, Pennsylvania

Galbraith DW, Harkins KR, Maddox JM, Ayres NM, Sharma DP, Firoozabady E (1983) Rapid flow cytometric analysis of the cell cycle in intact plant tissues. Science 220: 1049-1051

Galletta GJ (1975) Blueberries and cranberries. In Janick J, Moore JN (eds). Advances in fruit breeding. Purdue University Press, West Lafayette, Indiana, pp 154-196

Hall SH, Galletta GJ (1971) Comparative chromosome morphology of diploid Vaccinium species. J Am Soc Hort Sci 96:289-292

Keeler KH, Kwankin B, Barnes PW, Galbraith DW (1987) Polyploid polymorphism in Andropogon gerardii. Genome $29: 374-379$

Megalos BS, Ballington JR (1988) Unreduced pollen frequencies versus hybrid production in diploid-tetraploid Vaccinium crosses. Euphytica 39:271-278

Michaelson MJ, Price HJ, Ellison JR, Johnston JS (1991) Comparison of plant DNA contents determined by Feulgen microspectrophotometry and laser flow cytometry. Am J Bot $78: 183-188$

Price HJ (1976) Evolution of DNA content in flowering plants. Bot Rev 42:27-52

SAS Institute Inc. (1985) SAS/STAT ${ }^{\text {TM }}$ guide for personal computers, version 6 edn. SAS Institute Inc., Cary, North Carolina
Sharpe RH, Sherman BW (1971) Breeding blueberries for lowchilling requirement. HortScience $6: 3-5$

Smouse PE, Long JC, Sokal RR (1986) Multiple regression and correlation extensions of the Mantel test of matrix correspondence. Syst Zool 35:627-632

Sokal RR, Rohlf FJ (1981) Biometry 2nd edn. W. H. Freeman and Company, New York

Sparrow AH, Nauman AF (1976) Evolution of genome size by DNA doubling. Science 192:524-529

Steel RGD, Torrie JH (1980) Principles and procedures of statistics - a biometrical approach. 2nd edn. McGraw Hill Book Company, New York

Vander Kloet SP (1988) The genus Vaccinium in North America Research Branch Agriculture Canada, Pub. 1828

Verma SC, Rees H (1974) Nuclear DNA and the evolution of allotetraploid Brassicaceae. Heredity 33:61-68

Vorsa N (1984) A phenotypic, fertility and cytological study of backcross derivatives of the pentaploid hybrids of Vaccinium australe Small $\times$ Vaccinium ashei Reade. PhD dissertation, Rutgers University, New Brunswick, New Jersey

Vorsa N (1988) Differential transmission of extra genome chromosomes in pentaploid blueberry. Theor Appl Genet 75:585-591

Vorsa N, Ballington JR (1991) Fertility of triploid highbush blueberry. J Am Soc Hort Sci 116:336-341

Vorsa N, Jelenkovic G, Draper AD, Welker WV (1986) Aneuploid seedlings derived from pentaploid Vaccinium australe $\times$ $V$. ashei hybrids. J Hered 77:114-118

Vorsa N, Jelenkovic G, Draper AD, Galletta GJ (1987a) Crossability of $\mathrm{BC}_{1}$ aneuploid and tetraploid progeny derived from Vaccinium ashei/corymbosum pentaploid hybrids. J Am Soc Hort Sci 112:998-1004

Vorsa N, Jelenkovic G, Draper AD, Welker WV (1987b) Fertility of $4 \mathrm{x} \times 5 \mathrm{x}$ and $5 \mathrm{x} \times 4 \mathrm{x}$ progenies derived from Vaccinium ashei/corymbosum pentaploid hybrids. J Am Soc Hort Sci 112:993-997 